\title{
Thoracolumbar Region
}

National Cancer Institute

\section{Source}

National Cancer Institute. Thoracolumbar Region. NCI Thesaurus. Code C92597.

The region of the spinal cord pertaining to the thoracic and lumbar vertebrae. 